\title{
REFORMA TRABALHISTA E NEGOCIAÇÃO COLETIVA: VIOLAÇÃO A DIREITOS FUNDAMENTAIS
}

\author{
Bruno H. M. Pirolo1 \\ Lourival José de Oliveira ${ }^{2}$
}

Resumo: Objetivou-se examinar as alterações promovidas pela reforma trabalhista, em especial a ampliação do objeto de negociação coletiva frente à garantia dos direitos mínimos do trabalho humano. Concluiu-se que os direitos fundamentais laborais poderão ser mitigados, contrariando o estabelecido na Constituição Federal. Igualmente, constatou-se conflito direto com várias normas internacionais quando tratam da proteção de trabalhadores. Utilizou o método dedutivo, demonstrando-se que as alterações nos limites da negociação coletiva se tornaram contrárias às normas nacionais e internacionais de proteção aos direitos fundamentais laborais, sendo necessário aperfeiçoamentos.

Palavras-chave: Dignidade da pessoa humana. Direitos laborais. Intervenção internacional. Grupos vulneráveis. Poder normativo.

\section{LABOR REFORM AND COLLECTIVE BARGAINING: VIOLATION OF FUNDAMENTAL RIGHTS}

\begin{abstract}
The objective was to examine the changes promoted by the labor reform, in particular the extension of the object of collective bargaining vis-a-vis the guarantee of the minimum rights of human labor. It was concluded that fundamental labor rights can be mitigated, contrary to what is established in the Federal Constitution. Likewise, there was direct conflict with several international norms when dealing with the protection of workers. It used the deductive method, demonstrating that the changes in the limits of collective bargaining have become contrary to national and international norms for the protection of fundamental labor rights, being needed improvements.
\end{abstract}

Kew-words: Dignity of human person. Labor rights. International intervention. Vulnerable groups. Regulatory power.

\footnotetext{
${ }^{1}$ Especialista em Direito Previdenciário; Especialista em Direito Constitucional Contemporâneo; Mestrando no Programa de Mestrado da UNIMAR/SP; docente do curso de Graduação em Direito da Faculdade Dom Bosco C. Procópio/PR; advogado; e-mail: brunopirolo@ hotmail.com.

${ }^{2}$ Doutor em Direito das Relações do Trabalho (PUC-SP); docente associado do Curso de Graduação em Direito da Universidade Estadual de Londrina; docente dos Programas de Doutorado/Mestrado da Universidade de Marília; docente de vários Cursos de Especialização em Direito; advogado em Londrina; e-mail lourival.oliveira40@hotmail.com
}

Rev. de Direitos Fundamentais nas Relações do Trabalho, Sociais e Empresariais | e-ISSN: 2525-9903 | Maranhão | v. 3 | n. 2 | 


\section{INTRODUÇÃO}

Como parte do tema que será exposto no presente artigo, necessário se faz a apresentação de conceitos gerais sobre as próprias terminologias de direitos humanos, direitos fundamentais, direitos sociais e direitos laborais, sendo usual ocorrer confusões nas conceituações. Todavia não pode ocorrer a descontextualização dos significados.

Tais direitos nascem e se atualizam no campo pratico das sociedades com as mesmas perspectivas e objetivos de garantir direitos mínimos e necessários para sobrevivência do ser humano de forma digna.

No âmbito dos entes internacionais que possuem a responsabilidade de garantir direitos básicos e inerentes ao homem será apresentada evolução histórica e finalidades, visando demonstrar que os entes públicos internacionais podem (e devem) atuar na fiscalização, garantia e cobrança do cumprimento de direitos trabalhistas mínimos.

Por sua vez, a reforma trabalhista ocorrida através da Lei $n^{\circ} 13.467$, de 13 de julho de 2017, alterou diversos artigos da Consolidação das Leis Trabalho - CLT, modificando limites e valores da negociação coletiva que nitidamente podem trazer prejuízos e insegurança aos trabalhadores, considerados como grupo vulneráveis na relação laboral.

O objetivo é também verificar se as alterações da reforma trabalhista ocorridas no Brasil sobre as matérias que podem ser negociadas contrariam normas internacionais de proteção ao trabalho, de forma a legitimar a intervenção de entes internacionais de proteção ao trabalho.

O trabalho será dividido em capítulos, utilizando-se do método dedutivo e históricobibliográfico, com apresentação de evoluções e conceitos gerais dos temas relacionados e, de maneira específica, demonstrar a contrariedade das alterações na negociação coletiva frente direitos fundamentais.

\section{DIREITO DO TRABALHO}

O conceito de trabalho em si nasce com a própria natureza do homem, sendo que os primeiros registos Bíblicos comprovam essa afirmativa, demonstrando que antes mesmo do pecado original já se tinha o trabalho como ato humano.

Rev. de Direitos Fundamentais nas Relações do Trabalho, Sociais e Empresariais | e-ISSN: 2525-9903 | Maranhão | v. 3 | n. 2 | p. 1 - 22 | Jul/Dez. 2017. 
Portanto, do relato bíblico, o que se pode concluir é que, originalmente, o trabalho era algo prazeroso e desprovido de sacrifícios, dado que o homem gozava do dom preternatural da impassibilidade, pelo que não padecia doenças e sofrimentos no paraíso terreno. Depois do pecado original, esse mesmo trabalho, sem deixar de ser fonte de alegrias e realização pessoal na transformação do mundo, passou a ser algo que esforço e que, pelo sacrifício maior que possa supor, pode ser fonte de aviltamento do próprio homem. (FILHO, 2002, p. 34).

Com todas as evoluções humanas, partindo da escravidão, era do feudalismo, das corporações de oficio e, principalmente, das revoluções francesas e industriais, entre outras, o trabalho passa a ser inserido em um contexto jurídico de normas de direitos e deveres a serem respeitadas em harmonia com direitos fundamentais e sociais, também conquistados.

E dessa conjuntura, nasce o que se tem por Direito do Trabalho, salientando que atualmente, no ordenamento jurídico brasileiro, o respectivo direito é ramo autônomo e independente.

Conjunto de princípios, regras e instituições atinentes a relação do trabalho subordinado e situações análogas, visando assegurar melhores condições de trabalho e sociais ao trabalhador, de acordo com as medidas de proteção que lhe são destinadas. (MARTINS, 2015, p. 18, grifo nosso).

O âmbito do Direito do Trabalho é por excelência um dos principais a utilizar o conceito de dignidade da pessoa humana e dos direitos fundamentais por vincular a uma atividade inerente do ser humano e que deve ser dotada de garantias mínimas de dignidade em sua realização.

2.1 Fontes de direitos e deveres trabalhistas

Os direitos e deveres em relações laborais conquistados ao longo dos anos se encontram inseridos em diversas fontes do ordenamento jurídico brasileiro e internacional adotados pelo Estado Brasileiro.

Como principais fontes do Direito do Trabalho (material e processual) no Brasil se tem a Constituição Federal de 1988 que, principalmente, em seu artigo $7^{\circ}$ elenca de forma exemplificava XXIV incisos com garantias mínimas ao trabalhador. 
Ainda, a CLT, onde está inserida maioria das garantias dadas ao empregado e empregador em uma relação laboral e o Código de Processo Civil - CPC, também utilizado de forma subsidiária naquilo que a CLT é omissa (Art. 796 da CLT).

Ademais, muito utilizado e com grande importância no Direito do Trabalho, os acordos e convenções coletivas (sentenças normativas) são grandes fontes de matérias relacionados ao cotidiano laboral.

Por sua vez, no Direito Internacional do Trabalho as fontes de direitos e deveres não são diferentes e se apresentam de diversas maneiras, como em tratados, convenções e pactos firmados e ratificados por cada país. São em sua maioria formulados por entes públicos internacionais que possuem caráter independente e autônomo a qualquer Estado de Direito.

No contexto internacional de direitos e deveres trabalhistas os entes públicos internacionais detêm competência para criar normas, fiscalizar e garantir direitos trabalhistas mínimos, como por exemplo, a Organização Internacional do Trabalho - OIT e o Sistema Interamericano de Direitos Humanos - SIDH.

Os entes internacionais passaram a surgir, principalmente, após revoluções e guerras dos séculos XVIII, XIX e XX, onde os direitos tidos como fundamentais e inerentes ao homem começaram a ser incorporados nos Estados de direito e nas sociedades. Assim, se tornaram mecanismos indispensáveis para desenvolvimento e fiscalização de direitos mínimos do homem como ser humano. (PIOVESAN, 2015).

A OIT, por exemplo, possui como uma das funções fundamentais a elaboração, adoção, aplicação e promoção das Normas Internacionais do Trabalho, sob a forma de convenções, protocolos, recomendações, resoluções e declarações (OIT.b).

As principais regras laborais elaboradas pela OIT estão expressas nas convenções e recomendações que podem (e devem) ser ratificadas pelos países membros.

E o que também se denota no preambulo do PACTO DE SAN JOSE, responsável por regular o SIDH, que possuem decisões de casos concretos com temas laborais:

Reconhecendo que os direitos essenciais da pessoa humana não derivam do fato de ser ela nacional de determinado Estado, mas sim do fato de ter como fundamento os atributos da pessoa humana, razão por que justificam uma proteção internacional, de natureza convencional, coadjuvante ou complementar da que oferece o direito interno dos Estados americanos. (PACTO DE SAN JOSE). 
Ademais, as fontes de direito do trabalho provenientes dos tratados internacionais são qualificados como normas supraconstitucionais, já que possuem especial colocação no ordenamento jurídico, sendo correlacionado a própria norma constitucional.

A constituição de 1988 inova, assim, ao incluir dentre os direitos constitucionalmente protegidos, os direitos enunciados nos tratados internacionais de que o Brasil seja signatário. Ao efetuar tal incorporação, a Carta está a atribuir aos direitos internacionais hierarquia especial e diferenciada, qual seja, a de norma constitucional. (PIOVESAN, 2015, p. 63).

Portanto, são muitos os direitos e deveres de uma relação laboral, tanto de fontes nacionais como de internacionais (característica supraconstitucional), mas todas visam a garantir de forma mínima a dignidade do trabalhador e uma relação de trabalho justa, como um próprio direito humano.

2.2 Direito do trabalho como direito fundamental

Muitas são as confusões conceituais quando se tentam delimitar em significados singulares terminologias como direitos humanos (dignidade humana), direitos fundamentais, direitos sociais, direitos trabalhistas e outros. Sendo assim, não se quer aqui esgotar as fontes conceituais dessas terminologias, entretanto, importante traçar um caminho para cada uma delas.

Os direitos humanos podem ser entendidos como aqueles previamente existentes ao próprio Estado de Direito e a qualquer tipo de positivação, são direitos inerentes ao homem como ser humano e a dele não podem ser distanciados, portanto, são direitos naturais. (CANOTILHO, 2003).

Direitos esses, que conforme Bobbio (1992, p. 32) "não nascem todos de uma vez, nem de uma vez por todas". Sendo assim, os direitos humanos foram sendo reconhecidos ao longo das gerações, através de guerras, revoluções e demais acontecimento na história da humanidade e incorporados (positivados) nas ordens jurídicas de cada sociedade. 
Atualmente, o conceito de direitos humanos é contemporâneo, momento onde a grande maioria desses direitos passaram a ser reconhecidos e devidamente "exigidos" e fiscalizados pela própria sociedade em um contexto internacional.

Considerando a historicidade dos direitos, destaca-se a chamada concepção contemporânea de direitos humanos, que veio a ser introduzida pela Declaração Universal de 1948 e reiterada pela Declaração de Direitos humanos de Viena de 1993. (PIOVESAN, 2015, p. 8.).

Os direitos fundamentais, no que lhe concerne, mesmo que estejam englobados na relação de direitos humanos, podem ter uma particularização específica, que seria a sua própria positivação ou exteriorização em norma dentro de um Estado de direito, como exemplo o artigo $5^{\circ}$ da Constituição Federal Brasileira de 1988.

A criação de direitos fundamentais se assenta na escolha dos indivíduos, iguais e livres, que decidem legitimamente regular a vida coletiva pelo direito positivo. (HABERMAS, 1996). Ou seja, tem a necessidade de sua apresentação material e não abstrata no campo de garantias.

Portanto, os direitos fundamentais, que podem ser divididos em gerações de acordo com suas apresentações a sociedade, são aqueles mínimos necessários para uma vida digna de um ser humano na sociedade que vive. E por isso da confusão, pois se homogeneízam com direitos humanos, direitos inerentes ao convívio em sociedade e direitos futuros.

Por sua vez, o Direito do Trabalho é inserido nos direitos fundamentais de segunda geração, sendo inerente ao próprio direito do homem de forma abstrata, mas também, sendo positivado como direito fundamental-social e específico dentro do contexto das sociedades. (BOBBIO, 1992).

Nessa perspectiva, percebe-se que os direitos laborais sempre existiram, sendo da ordem natural do homem (direitos humanos), passando a serem positivados nos Estados de Direito (direitos fundamentais) dentro de um contexto próprio e independente de direitos sociais e trabalhistas:

Se o capitalismo mercantil e a luta pela emancipação da sociedade burguesa são inseparáveis da consciencialização dos direitos do homem, de feição individualista, a luta das classes trabalhadoras e as teorias socialistas põem em relevo a unidimensionalização dos direitos do homem e a necessidade de completar (ou substituir) os tradicionais direitos do cidadão burguês pelos direitos do homem total. (CANOTILHO, 2003, p. 385). 
E, ainda, ratificando a colocação dos direitos trabalhistas como sociais, fundamentais e humanos a autora Flávia Piovesan descreve (2015, p. 191) “finalmente, há um conjunto de decisões que consagram a proteção indireta de direitos sociais, mediante a proteção de direitos civis, o que confirma a ideia da indivisibilidade e da interdependência dos direitos humanos".

Deste modo, o direito do trabalho deve ser tradado como um direito fundamental e humano, pois o é, como próprio direito do homem como pessoa.

\section{ENTES PÚBLICOS INTERNACIONAIS E DIREITOS LABORAIS FUNDAMENTAIS}

A preocupação com a questão dos direitos humanos passou a ser mais presente e positivada pós Segunda Guerra Mundial. Os principais instrumentos de proteção desses direitos surgem da tentativa de evitar que acontecimentos que violaram direitos mínimos de vida ocorressem novamente.

Desta maneira, em 1945 foi criada a ONU (Organização das Nações Unidas) com assinatura da Carta Das Nações Unidas elaborada por mais de 50 países e posteriormente ratificadas por EUA, China, ex-União Soviética e outros signatários. (ONU.a).

A ONU hoje é a principal organização internacional na defesa e fiscalização da garantia dos direitos mínimos do ser humano. O preambulo da Carta das Nações Unidas representa todos seus princípios:

Nós, os povos das Nações Unidas, resolvidos a preservar as gerações
vindouras do flagelo da guerra, que, por duas vezes no espaço da nossa vida,
trouxe sofrimentos indizíveis à humanidade, e a reafirmar a fé nos direitos
fundamentais do homem, na dignidade e no valor do ser humano, na igualdade
de direitos dos homens e das mulheres, assim como das nações grandes e
pequenas, e a estabelecer condições sob as quais a justiça e o respeito às
obrigações decorrentes de tratados e de outras fontes de direito internacional
possam ser mantidos, e a promover o progresso social e melhores condições
de vida dentro de uma liberdade mais ampla [...]. (ONU.b).

Como todo mecanismo que busca essa evolução da sociedade ainda é pouco, em 1948 foi fundada a OEA (Organização dos estados americanos), que foi conglomerada por vários 
protocolos ao longo dos anos. Atualmente, a OEA agrega 35 estados independentes das Américas e tem como princípios bases: a democracia, direitos humanos, segurança e desenvolvimento. (OAS.a).

No mesmo passo, existem entes internacionais monitoram especificamente os direitos trabalhistas, como a Organização Internacional do Trabalho - OIT e Sistema Interamericano de Direitos Humanos - SIDH que se verá nos tópicos que seguem de forma específica.

Sendo que todos exercem de forma autônoma e independente o papel de desenvolvedores, fiscalizadores e de certa coação frente o cumprimento dos direitos humanos, fundamentais, sociais, trabalhistas e outros mínimos conquistados ao longo dos anos, tendo papel essencial na garantia de tais direitos através de mecanismos próprios.

\subsection{Organização Internacional do Trabalho - OIT}

A OIT foi criada em 1919, antes mesmo da ONU (1945), após o fim da Primeira Guerra Mundial, como parte do Tratado de Versalhes. Fundou-se no pilar da necessidade da justiça social para atingir a paz permanente. Possui estrutura tripartite, composta de representantes de governos e de organizações de empregadores e de trabalhadores. (OIT.b)

Tem como principal responsabilidade a formulação e aplicação das normas internacionais do trabalho, ou seja, está ligada intimamente ao direito laboral global. O Brasil está entre os membros fundadores da OIT e participa da Conferência Internacional do Trabalho desde sua primeira reunião.

Durante os primeiros anos de existência a OIT consagrou a maior parte de suas energias a desenvolver normas internacionais do trabalho e a garantir sua aplicação, tendo suas atividades amenizadas no âmbito da Segunda Guerra Mundial.

Após o fim da grande guerra a OIT reafirmava o princípio de que a paz permanente só pode estar baseada na justiça social e estabelecia quatro ideias fundamentais, que constituem valores e princípios básicos da OIT, podendo ser citadas: o trabalho como fonte de dignidade; o trabalho não se trata de mercadoria; que a pobreza é uma ameaça ao bem estar de todos, à liberdade, à segurança econômica e à igualdade de oportunidades.

Ademais, percebe-se que A OIT desempenha um papel importante na definição de legislações trabalhistas e na elaboração de políticas econômicas, sociais e trabalhistas como fundamentais, sendo que, atualmente, ela possui quatros sistemáticas de operação:1. Comissão 
de Peritos para a Aplicação das Convenções e das Recomendações (CEACR); 2. Comitê de Aplicação das Normas da Conferência (CAS); 3. Reclamações e Queixas Entregues ao Conselho da Administração; e, 4. Comitê de Liberdade Sindical. (OIT.b).

\begin{abstract}
A OIT é diretamente ligada às relações laborais no contexto internacional, tendo como base suas convenções e recomendações. "As convenções que são normas jurídicas provenientes da Conferencia da OIT, tendo por objetivo determinar regras gerais e obrigatórias para os Estados que as ratificarem, passando a fazer parte de seu ordenamento jurídico interno". (MARTINS. 2014, p, 215).
\end{abstract}

Atualmente, existem 189 convenções com algumas canceladas e outras alteradas. O Brasil ratificou a maioria delas, como por exemplo, as convenções 98 e 154, que possuem temática de negociação coletiva. (OIT.b). "As recomendações, por sua vez, são normas da OIT em que não houveram um número suficiente de adesões para que ela viesse a se transformar para sua materialidade em convenção" (MARTINS, 2014, p, 16), mas que possuem força de conscientização

Quando não há a ratificação por um Estado de convenção ou recomendação, a OIT se demonstra aflita frente a falta de garantia para a sociedade, sendo que determinado tema já reconhecido pela OIT como regra geral de direito, fica sem a necessidade de garantia interna de um país.

Nesses casos, a OIT trabalha sempre visando as ratificações das convenções e recomendações, para que não existam reflexos contrários a normas fundamentais nas sociedades de determinados países que não ratificam uma ou outra norma internacional.

Por exemplo, a convenção 87 da OIT que expõe sobre a liberdade sindical e a proteção do direito de sindicalização, dando maior liberdade e equidade para sindicatos, empresas e trabalhadores em regular suas normas especificas, ainda, não foi ratificada pelo Brasil, sendo constantemente "pressionada" ratificá-la.

Portanto a OIT, conforme (MARTINS, 2014, p. 85) "prega a universalidade, pois, suas normas devem ser observadas no mundo todo. [...] Não tem por objetivo impor determinações, mas persuadir os países a aplicarem certos procedimentos".

Não se pretende aqui esgotar o conteúdo sobre a OIT e sim apresentar de forma geral sua existência, o que engloba e seus mecanismos de análise de casos concretos, visando instigar

Rev. de Direitos Fundamentais nas Relações do Trabalho, Sociais e Empresariais | e-ISSN: 2525-9903 | Maranhão | v. 3 | n. 2 | 
a reflexão da possibilidade de ser levado a ela as alterações trabalhistas, principalmente sobre a negociação coletiva.

\subsection{Sistema Interamericano de Direitos Humanos - SIDH}

Entre várias outras cartas, organizações, comissões e sistemas nacionais e internacionais, foi criado em 1959 a Comissão interamericana de direitos humanos - CIDH, onde já em 1961 iniciaram as inspeções in loco nos países da América para a investigação das situações reais quanto a garantia de direitos humanos.

Em 1965 a CIDH iniciou os procedimentos de receber e processar casos particulares nos quais se alegava violação de direitos humanos no âmbito dos Estados Americanos. Ela realiza seu trabalho em três pilares: peticionamento individual, monitoramento da situação dos direitos humanos nos estados membros e atenção a linhas temáticas prioritárias.

Em 1969 foi aprovada a Convenção Americana sobre Direitos Humanos (PACTO SAN JOSE DA COSTA RICA), maior instrumento normativo de garantias aos direitos humanos mínimos a uma vida digna que inserido ao SIDH são os principias meios de fiscalização e cumprimento dos direitos humanos no contexto americano.

Sendo assim, toda essa sistemática da CIDH, com suas normas, estatutos, pactos, corte e atividades de fiscalização e cobrança do cumprimento de direitos, temos a materialização do chamado SIDH. Importante salientar que todas matérias ou casos, assim chamados, levados através de petição para a CIDH, passam por uma análise prévia de cabimento ou não, para somente após sua aceitação possam ser iniciados os procedimentos de real verificação da situação.

Para que ocorra a concordância e abertura do procedimento, o caso apresentado necessita preencher os requisitos para tanto, sendo nesse ponto a importância do presente trabalho, ou seja, apresentar que matéria trabalhista, principalmente a reforma trabalhista negociação coletiva, está inserida na possibilidade de análise de casos concretos pelo SIDH.

O SIDH tem responsabilidade na valoração e na garantia de direitos mínimos das relações laborais dentro do contexto interamericano. Como por exemplo, no art. $6^{\circ}$ do Pacto de San Jose, adotado pela SIDH: 
Artigo $6^{\circ}$ - Proibição da escravidão e da servidão ninguém deve ser constrangido a executar trabalho forçado ou obrigatório. Nos países em que se prescreve, para certos delitos, pena privativa de liberdade acompanhada de trabalhos forçados, esta disposição não pode ser interpretada no sentido de proibir o cumprimento da dita pena, imposta por um juiz ou tribunal competente. $\mathrm{O}$ trabalho forçado não deve afetar a dignidade, nem a capacidade física e intelectual do recluso. (PACTO DE SAN JOSE).

Segundo Piovesan: “A SIDH estabelece um aparato de monitoramento e proteção dos direitos que enuncia, integrado pela comissão e pela corte interamericana de direitos humanos". (PIOVESAN, 2015, p, 98).

Portanto, o SIDH possui a responsabilidade normativa e de valor para proteger direitos fundamentais e, por ora, trabalhistas no contexto interamericano, utilizando para tanto seus mecanismos de peticionamento (na maioria das ocasiões são realizados por entidades não governamentais), monitoramento e atenção a linhas especiais, levando ao crivo do CIDH situações concretas, inclusive com verificações in loco e penalizações, entre outros procedimentos legais.

Não se pretende aqui esgotar o conteúdo do SIDH e sim apresentar de forma geral sua existência, o que engloba e seus mecanismo de atuação para fomentar a reflexão da possibilidade de matérias trabalhistas também serem levadas ao crivo da CIDH.

\section{REFORMA TRABALIHISTA}

Assim ficou denominada o projeto de lei 6.787/2016 que após a aprovação e sanção foi transformada na Lei $\mathrm{n}^{\mathrm{o}}$ 13.467, de 13 de julho de 2017, que alterou múltiplos artigos da Consolidação das leis Trabalhistas - CLT.

A matéria foi de grande polemica no contexto nacional, onde defendiam sua necessidade para modernizar a relação laboral, e, outros defendiam a ideia de supressão de direitos sociais-trabalhistas conquistados ao longo dos anos, enfraquecendo, ainda mais, a parte hipossuficiente na relação laboral.

Destarte, após a aprovação da reforma, a polemica e a reflexão devem pairar sobre se tais alterações se apresentam constitucionais e/ ou se no campo pratico do cotidiano das relações 
laborais ocorrerão ocasiões que vão em caminho inversos das garantias promovidas pelos direitos humanos, fundamentais e trabalhistas, devendo, nesse ponto serem condenadas.

Muitas foram as alterações e todas elas com suas particularidades e discussões. Por exemplo, quanto ao direito material: a nova divisão de férias, jornada de trabalho, transporte do trabalhador, home office entre outros. No contexto de direito processual, tem-se a alteração da regra dos danos morais, custas processuais, honorários entre outras.

Alterações essas que autorizam que diversas matérias que passaram a ser objeto de negociação coletiva possam vir a ter prevalência sobre a lei em inúmeras oportunidades, contrariando em especial o princípio da norma mais benéfica, insculpida no artigo $7^{\circ}$ "caput" da Constituição Federal como também o que ficou estabelecido no artigo 170 da mesma carta.

Neste passo, um dos questionamentos que se apresenta é quanto à possiblidade dos entes públicos internacionais possuírem instrumentos, ou melhor, competência e capacidade para a fiscalização e garantia dos direitos fundamentais laborais, possibilitando a interferência internacional através deles a fim de expungir os resultados de negociações coletivas que agridam esses mesmos direitos.

Logicamente que não se descarta os instrumentos e entes internos de proteção, como por exemplo, o Ministério Público do Trabalho e os próprios sindicatos. Contudo, é possível que venha a surgir a necessidade da reunião das proteções nos dois planos, nacional e internacional, para possibilitar uma razoável condição de defesa dos direitos fundamentais trabalhista.

\subsection{Reforma trabalhista e negociação coletiva}

Entre todas as alterações produzidas pela chamada reforma trabalhista, a que mais chama a atenção trata-se das mudanças que ocorreram no que se refere a ampliação das matérias que podem ser objeto de negociação coletiva e nos seus próprios valores.

A negociação coletiva é um procedimento extrajudicial, no âmbito das relações materiais de trabalho que podem resultar no acordo coletivo ou convenção coletiva, contendo regras que segundo o artigo $7^{\circ}$ "caput" da Constituição Federal, devem conter normas e regras que melhorem as condições sociais dos trabalhadores.

Rev. de Direitos Fundamentais nas Relações do Trabalho, Sociais e Empresariais | e-ISSN: 2525-9903 | Maranhão | v. 3 | n. 2 | 
Negociação coletiva compreende todas as negociações que tenham lugar entre, de uma parte, um empregador, um grupo de empregadores ou uma organização ou várias organizações de empregadores e, de outra parte, uma ou várias organizações de trabalhadores, visando: (a) fixar as condições e trabalho e emprego; (b) regular as relações entre empregadores e trabalhadores; (c) disciplinar as relações entre empregadores ou suas organizações e uma ou várias organizações de trabalhadores ou alcançar todos esses objetivos de uma só vez. (MARTINS, 2015, p. 889).

Possuem previsão legal, entre outras fontes, nos artigos 611 a 625 da CLT, tendo alterações nos artigos 611-A, 611-B, 614, § $3^{\circ}$ e 620.

O novo artigo 611-A da CLT, passou a autorizar que convenção coletiva e acordo coletivo tenham prevalência quanto a lei em várias oportunidades como na jornada de trabalho, teletrabalho, sobreaviso, trabalho intermitente, labores com insalubridade, e outros.

Sendo assim, muitas situações do cotidiano laboral poderão ser alteradas, visando reduzir os custos da empresa e consequentemente mitigando direitos do trabalhador, além do fato da contrariedade quanto ao princípio da norma mais favorável vigente frente o trabalhador.

Por exemplo, regras quanto a jornadas de trabalho (inciso I) e bancos de hora (inciso II) que podem se tornar mais prejudiciais ao trabalhador, tanto as tornando mais rígidas, dificultado escolhas do trabalhador, quanto, tornando-as mais maleáveis sem respeitar proteções mínimas da relação empregatícia.

O regime de sobreaviso que poderá não contar mais como horas trabalhadas, aumentando a jornada de trabalho e diminuindo a base salarial do empregado. $\mathrm{O}$ trabalho intermitente, o qual não havia regulamentação e com a reforma passa a ser legal a contratação e pagamento do trabalhador por horas trabalhadas, flexibilizando e enfraquecendo a relação empregatícia (ambos inciso VII).

A troca do dia de feriado (inciso XI), onde o trabalhador possuía a garantia de descanso agora fica a interesse de a empresa alterar datas que lhe convenham. Outro caso é a insalubridade (inciso XII), onde a empresa poderá prorrogar jornada de trabalho em ambientes insalubres, sem autorização prévia de autoridades competentes, sem falar na possibilidade de negociação sobre condições ligadas diretamente à segurança e medicina do trabalho (Art. 7, XXII da CF/88).

Outra alteração preocupante foi a realizada no artigo 614, $\S 3$ da CLT, o a qual não permite a ultratividade do resultado da negociação coletiva após dois anos, prazo fixado como 
máximo de validade. Sendo assim, após findado o prazo máximo de 2 anos, imposto como prazo máximo de validade de um acordo/ convenção, enquanto não for aprovada novo acordo/ convenção aquele anterior perde a eficácia. Ou seja, no lapso temporal entre o fim de um acordo e a homologação de um novo, a relação laboral fica à mercê de regras gerais, as quais podem não garantir direitos específicos anteriormente previstos para determinada categoria, o que contraria diretamente a cláusula implícita do não retrocesso social.

E, ainda, a nova redação do artigo 620 da CLT, que mitiga o próprio princípio da proteção e da norma mais favorável ao trabalhador de forma objetiva. Tal modificação não faz sentido e como resultado os empregadores terão maior força para alterar regras através de acordos coletivos que prevalecerão sobre convenções coletivas, ou seja, a regra de menor abrangência supera a de maior abrangência, podendo acarretar, por exemplo, em situações diferentes para a mesma categoria em uma mesma localidade. Deitou por terra mais uma vez o princípio da norma mais favorável.

Enfim, através de uma rápida reflexão sobre as alterações realizadas, nota-se que o empregador terá força desproporcional nas mesas de negociação e que as matérias e valores que agora podem ser discutidas irão atingir direitos mínimos do trabalhador previstos na norma constitucional e supraconstitucional.

Inclusive, esse é o entendimento do Desembargador Bruno da Costa Rodrigues (2017) sobre a forças desiguais em se tratando de negociação coletiva após as alterações sancionadas, jurista esse ligado diretamente aos casos do cotidiano laboral:

Ressalvadas exceções setoriais, a realidade demonstra que não há sindicatos de trabalhadores efetivamente representativos, não há liberdade para os trabalhadores escolherem outra entidade que seria mais representativa e não há mobilização de trabalhadores dentro dos interesses de cada contexto profissional com força suficiente para fazer frente a qualquer negociação coletiva.

Conforme Sergio Pinto Martins (2015, p. 891) “[...] importante destacar que a finalidade da negociação coletiva é a obtenção da paz social entre as partes”. E as mudanças, caso a analise seja inserida em um contexto político-econômico-cultural presente no Brasil, se apresentam com preponderância de mitigação de direitos dos trabalhadores, que é grupo vulnerável na relação. 
O autor Mauricio Godinho Delgado (2009, p. 1284) traz a luz em consonância com essa afirmação o conceito do princípio do da adequação setorial negociada, ou seja, as normas coletivas podem se contrapor as normas individuais imperativas estatais quando respeitados dois critérios objetivamente fixados: quando as normas coletivas implementam normas gerais e quando normas coletivas transacionam setorialmente parcelas trabalhistas de indisponibilidade relativa.

No caso brasileiro, esse patamar civilizatório mínimo está dado, essencialmente, por três grupos convergentes de normas trabalhistas heterônomas: as normas constitucionais em geral [...], as normas de tratados e convenções internacionais vigorantes no plano interno brasileiro [...], as normas legais infraconstitucionais que assegurem patamares de cidadania ao indivíduo que labora [...]. (DELGADO, 2009, p. 1286)

As regras previstas na $\mathrm{CF} / 88$ (por exemplo o art. $7^{\circ}$ e seus incisos), as normas supraconstitucionais (previstas nos tratados internacionais ratificados) e outras de caráter infraconstitucionais (mas que garantam direitos mínimos), devem ser consideradas e estimuladas e não percorrer o caminho inverso em matéria de negociação coletiva, entendimento esse majoritário e caminho natural da interpretação de normas fundamentais.

\section{MECANISMOS INTERNACIONAIS DE PROTEÇÃO A DIREITOS FUNDAMENTIAS}

Em um contexto atual, as relações laborais e as alterações na negociação coletiva se apresentam em um conjunto nebuloso, não se sabendo, ainda, quais serão os reflexos de tais mudanças no cotidiano laboral da sociedade brasileira, mas por certo poderão precarizar as relações de trabalho no Brasil.

O Direito do Trabalho, o qual é um direito fundamental, possui características de direito privado e público e são expressos na ordem nacional e internacional das sociedades. O Direito Internacional do Trabalho, por sua vez, é um ramo independente e autônomo, possuindo regras e estruturas próprias fundidas em três bases: ordem econômica, índole social e caráter técnico. (Mazzuoli, 2015). 
Assim, as regras nacionais e internacionais de Direito do Trabalho no Brasil e o entes internacionais de proteção aos mesmos direitos possuem natural conexão. Para Canotilho (2003, p. 820) “as normas de direito internacional geral são parte integrante do Direito Federal, se acrescenta que essas normas prevalecem sobre leis, criando de forma directa, direitos e obrigações para os habitantes do território federal."

Entes como a OIT, especifico para o Direito do Trabalho, possui prerrogativa para análise de casos reais que possam se materializar no cotidiano laboral, por meio de seus instrumentos legais como as Conferencias realizadas anualmente, através dos seus comitês (liberdade sindicato e de peritos para aplicação das convenções e recomendações) e por meio de seu banco de dados, reclamações e queixas.

[...] dentro do acordo constitutiva da OIT não há uma enumeração inflexível de sua competência, o que deve ser auferido de acordo com cada momento que a humanidade atravessa. Ou seja, a OIT se ocupada daquilo que está de acordo com suas finalidades, não existindo uma enumeração rígida e uma limitação de seu âmbito e ação. (Mazzuoli, 2015, p. 1119).

Como visto, a OIT promove convenções e recomendações resultantes de discussões e debates de situações praticas que ocorrem em todo globo, com as ratificações pelos países as convenções se tornam normas legais (supraconstitucionais) a serem cumpridas.

Muitas temáticas de convenções da OIT tratam de temas que poderão ser mitigados com a nova forma de negociação coletiva, por exemplo: Convenção ${ }^{\circ} 95$, que trata da proteção ao salário, Convenção n ${ }^{\circ}$ 103, que trata do amparo à maternidade, Convenção no 106, que trata do repouso semanal, Convenção $n^{\circ} 115$, que trata da proteção contra as radiações, dentre outras.

Ou, ainda, quando a matéria não se consolida em convenção, ela tem força de recomendação, não sendo vista como norma que pode acarretar em imbróglio jurídico, mas, também, possuem diretrizes a serem compartilhadas, podendo sofrer afrontas com as alterações na negociação coletiva.

Como exemplo de recomendações da OIT que poderão sofrer abrandamentos pela reforma trabalhista se tem a recomendação sobre a própria promoção da negociação coletiva (163), segurança e saúde no trabalho na agricultura (192) que possui relação com atividades 
insalubres e, também, quanto a relação de trabalho e suas generalidades (198), entre outros. (OIT.a)

Portanto, a OIT possui prerrogativas, devendo ser um mecanismo de auxilio quanto a fiscalização de normas mínimas trabalhistas frente as alterações na negociação coletiva, utilizando seus instrumentos para análise da própria alteração em si e de casos concretos que poderão passar a acontecer, contrariando convenções e recomendações. Conforme Sérgio Pinto Martins define (2014, p. 84) “A livre associação sindical e a negociação coletiva são consideradas direitos fundamentais pela OIT”. E no caso, com a ampliação das matérias objeto de negociação, referida cláusula precisa de fato acontecer.

Outro exemplo de ente internacional que possui prerrogativa de garantir a proteção de direitos trabalhistas é o SIDH, que através do PACTO DE SAN JOSE, onde apresenta no seu artigo $8^{\circ}$ conteúdo que autoriza que relações laborais possam fazer parte do contexto de fiscalização e cobranças do sistema:

\footnotetext{
Artigo $8^{\circ}$ - Garantias judiciais

1. Toda pessoa terá o direito de ser ouvida, com as devidas garantias e dentro de um prazo razoável, por um juiz ou Tribunal competente, independente e imparcial, estabelecido anteriormente por lei, na apuração de qualquer acusação penal formulada contra ela, ou na determinação de seus direitos e obrigações de caráter civil, trabalhista, fiscal ou de qualquer outra natureza. (PACTO DE SAN JOSE).
}

Percebe-se por uma rápida análise do SIDH que a maioria dos casos que são aceitos e levados a tentativa de solução possuem conotação penal, de prática de crimes contra direitos mínimos garantidos. Entretanto, o próprio PACTO DE SAN JOSE alimenta a possibilidade de verificações sobre o direito trabalhista.

Ademais, como visto, tais direitos trabalhistas são integrantes dos próprios direitos humanos e fundamentais (supraconstitucionais), sendo garantias conquistadas ao longo das gerações pelas sociedades proletárias vulneráveis.

A autora Flavia Piovesan (2015, p. 106 a 114) traz algumas classificações interessantes quanto os casos levados a análise da Corte Interamericana de Direitos Humanos - CIDH:

Considerando a atuação da Corte Interamericana, é possível criar uma tipologia de casos baseadas em decisões concernentes a seis diferentes categorias de violação a direitos humanos: 1) Violações que e refletem o

Rev. de Direitos Fundamentais nas Relações do Trabalho, Sociais e Empresariais | e-ISSN: 2525-9903 | Maranhão | v. 3 | n. 2 | 
legado do regime autoritário ditatorial; 2) Violações que refletem questões da justiça de transição; 3) Violações que refletem desafios acerca do fortalecimento de instituições e da consolidação do Estado de Direito; 4) Violações de direitos de grupos vulneráveis; 5) Violações a Direitos Sociais 6) Violações a novos direitos da agenda contemporânea.

Desta feita, percebe-se que matérias relacionadas ao Direito do Trabalho estão vinculadas a muitas tipificações dos casos já levados a Corte. Como por exemplo, a violência contra a mulher, a discriminação racial em relações laborais, a violação de direitos de grupos vulneráveis (trabalhadores) e a violação a direitos sociais, entre outros.

Através do procedimento de peticionamento, são numerosos os exemplos de casos que passaram a crivo da SIDH com matérias laborais, por exemplo o Relatório n. 95/03, Petição 11.289, José Pereira, sobre trabalho escravo no Brasil, o qual houve decisão amistosa. (OAS.c).

Outros casos de proteção indireta de direitos sociais atem-se a proteção ao direito ao trabalho, tendo como fundamento o direito ao devido processo legal e a proteção social. A respeito, destaca-se o caso Baena Ricardo y otros versus Panamá (2001), envolvendo a demissão arbitraria de 270 funcionários públicos que participaram de manifestação (greve) (PIOVESAN, 2015, p. 114, itálico do autor).

São várias as situações concretas em que o SIDH poderá intervir, além do próprio ato de alterar as normas, como por exemplo, com a amplitude da negociação coletiva poderá ocorrer excessos de jornada, liberalidade para gravidas laborarem em condições insalubres, limitação do princípio da proteção que vigora no direito do trabalho, entre outras.

As alterações na negociação coletiva são casos claros de violação a direitos sociais e de grupos vulneráveis, já que o trabalhador, parte hipossuficiente para não perder o emprego aceitará situações que direitos mínimos não estarão garantidos, se encaixando assim nos casos passiveis de análise pelo SIDH.

A própria justiça do trabalho já possui diversos entendimentos sobre a infensa de matérias inseridas em negociação coletiva quanto a direitos inerentes ao homem, sendo que tais situações tendem a aumentar.

Súmula n ${ }^{\circ} 437$ do TST - INTERVALO INTRAJORNADA PARA REPOUSO E ALIMENTAÇÃO.

II - É inválida cláusula de acordo ou convenção coletiva de trabalho contemplando a supressão ou redução do intervalo intrajornada porque este

Rev. de Direitos Fundamentais nas Relações do Trabalho, Sociais e Empresariais | e-ISSN: 2525-9903 | Maranhão | v. 3 | n. 2 | 
constitui medida de higiene, saúde e segurança do trabalho, garantido por norma de ordem pública (art. 71 da CLT e art. $7^{\circ}$, XXII, da CF/1988), infenso à negociação coletiva.

Portanto, claro que SIDH possui prerrogativa e força para decisões em casos de direitos laborais, devendo ser um mecanismo de auxilio, utilizando seus instrumentos de peticionamento individual, monitoramento da situação dos direitos humanos nos Estados membros e atenção a linhas temáticas prioritárias, para análise da própria alteração em si da negociação coletiva e de e casos concretos que poderão acontecer contrariando normas supraconstitucionais de caráter fundamental.

Uma vez aceita a competência do tribunal, o Estado se obriga em relação ao fiel cumprimento daquilo que foi estabelecido na sentença, devendo cumprila de boa-fé, sob pena de responsabilidade internacional. [...], não se pode deixar de levar em consideração que o Direito Internacional tem outros meios - nem sempre jurídicos - de conduzir o Estado ao cumprimento do que foi decidido [...]. (Mazzuoli, 2015, p. 1179 e 1180).

Percebe-se que os direitos laborais, a reforma sancionada e os entes internacionais estão interligados por várias vertentes como previsão, funcionalidade, inserção, colisão de direitos, fiscalização, materialidade, cobranças e coações. "A crescente necessidade de cooperação internacional, nos mais diversos campos de aplicação do Direito, fez levar a criação e desenvolvimento de instituições internacionais, capazes de coordenar os interesses da sociedade internacional relativos a diversas finalidades”. (MAZZUOLI, 2015, p. 657).

Assim, resta demonstrado a necessidade e legalidade de se levar casos dessa área do direito para o âmbito dos entes internacionais para que através de seus mecanismos possam analisar e julgar possíveis infrações frente a garantia de direitos fundamentais assegurados.

\section{CONCLUSÃO}

A pesquisa se pautou na análise de direitos mínimos (humanos, fundamentais e laborais), comparando com o que foi aprovada na reforma trabalhista ( Lei $n^{\circ}$ 13.467/;2017), dando ênfase para a autotutela coletiva, como também, na apresentação da estrutura e sistemática de entes internacionais de proteção a esses direitos, demonstrando não apenas a

Rev. de Direitos Fundamentais nas Relações do Trabalho, Sociais e Empresariais | e-ISSN: 2525-9903 | Maranhão | v. 3 | n. 2 | 
legitimidade desses mesmos para intervirem nos pactos internos, resultados de negociações coletivas, como também na adoção de medidas internacionais que visem a impedir o cometimento de danos aos direitos sociais laborais.

Também como resultado, ficou comprovada que a denominada reforma trabalhista (Lei $\mathrm{n}^{\mathrm{o}}$ 13.467/2017) se apresentou em parte inconstitucional, por violador o mínimo estabelecido constitucionalmente, em especial o contido no artigo $7^{\circ}$ "caput" da Constituição Federal. Também, por impor às relações de trabalho parâmetros de liberdade encontrados nos negócios privados, ou seja, naqueles que estão desprovidos de direitos sociais/ fundamentais.

No plano internacional, os entes internacionais, em especial a Organização Internacional do Trabalho, possui legitimidade e mais do que isso, o dever de acompanhar a aplicação das mudanças impostas pela reforma trabalhista, em especial no que se refere à negociação coletiva de trabalho, considerando seus postulados básicos e finalidades perseguidas, o mesmo acontecendo com a Comissão Interamericana de Direitos Humanos. Inclusive, mesmo as Convenções Internacionais não ratificadas pelo Brasil poderão servir como parâmetros para correções pelo judiciário das cláusulas resultantes dos acordos ou convenções coletivas de trabalho, na forma do artigo $5^{\circ}$, parágrafo $2^{\circ}$ da Constituição Federal. É importante destacar que o controle das violações dos direitos sociais/fundamentais laborais não se faz apenas no plano interno. Que esse controle, fiscalização e imposição de medidas corretivas cabem também aos entes internacionais, que por certo estarão intervindo a fim de não deixar que aconteça o retrocesso social. Muito embora a reforma trabalhista tenha possibilitado a negociação coletiva e também individual sobre direitos indisponíveis, os mesmos continuam indisponíveis e o seu controle deverá acontecer de forma efetiva, cabendo aqui necessariamente o controle internacional, que de forma articulada funcionará em conjunto com os instrumentos internos de proteção.

\section{REFERÊNCIAS}

BOBBIO. Norberto. Era dos direitos. São Paulo: Campus, 1992.

BRASIL. Tribunal Superior do Trabalho. Súmula n. 437. Intervalo intrajornada para repouso e alimentação. Disponível em:

<http://www3.tst.jus.br/jurisprudencia/Sumulas_com_indice/Sumulas_Ind_401_450.ht ml\#SU M-437>. Acesso em 20 de Agosto de 2017. 
CANOTILHO. José Joaquim Gomes. Direito Constitucional e teoria da constituição. Ed. 7. Coimbra: Almedina, 2003.

DELGADO. Mauricio Godinho. Curso de Direito do Trabalho. ED. 8. São Paulo: LTr, 2009.

FILHO. Ives Gandra da Silva Martins. Manual do trabalho voluntário e religioso: aspectos fiscais, previdenciários e trabalhistas. São Paulo: LTr, 2002.

HABERMAS. Jürgen. Direito e democracia: entre facticidade e validade. São Paulo: Tempo Brasileiro, 1996.

MARTINS. Sergio Pinto. Direito do Trabalho. Ed. 31. São Paulo: Atlas, 2015.

MARTINS. Sergio Pinto. Instituições de Direito Público e Privado. Ed. 14. São Paulo: Atlas, 2014.

MAZZUOLI. Valerio de Oliveira. Curso de Direito Internacional público. ED. 9. São Paulo: Revista dos Tribunais, 2015.

OAS.a. Disponível em: <http://www.oas.org/pt/sobre/quem_somos.asp>. Acesso em Acesso em 10 de julho de 2017.

OAS.b. Disponível em:

<http://www.oas.org/dil/port/tratados_A41_Carta_da_Organiza\%C3\%A7\%C3\%A3o_dos_Est ados_Americanos.htm\#ch1>. Acesso em 10 de julho de 2017.

OAS.c. Disponível em: <http://www.oas.org/pt/cidh/decisiones/amistosas.asp>Acesso em 06 de agosto de 2017.

OIT.a. Disponível em: <http://www.ilo.org/brasilia/convencoes/lang--pt/index.htm>. Acesso em 10 de julho de 2017.

OIT.b. Disponível em: <https://nacoesunidas.org/conheca/historia/>. Acesso em 10 de julho de 2017.

OLIVEIRA, Lourival José de. Direito do Trabalho segundo o princípio da valorização do trabalho humano. LTR: São Paulo, 2011, p. 26.

ONU.a. Disponível em: <https://nacoesunidas.org/conheca/historia/>. Acesso em 10 de julho de 2017.

ONU.b Disponível em: <https://nacoesunidas.org/carta/>. Acesso em 10 de julho de 2017. Pacto de San Jose. Disponível em:

<http://www.pge.sp.gov.br/centrodeestudos/bibliotecavirtual/instrumentos/sanjose.htm>.

Acesso em 10 de Julho de 2017.

Rev. de Direitos Fundamentais nas Relações do Trabalho, Sociais e Empresariais | e-ISSN: 2525-9903 | Maranhão | v. 3 | n. 2 | 
PIOVESAN. Flavia. Temas de Direitos Humanos. Ed. 8. São Paulo: Saraiva, 2015.

RODRIGUES. Bruno da Costa. Negociação coletiva representa fim de direitos sem revogalos. Conjur, Campinas, jul. 2017. Disponível em: < http://www.conjur.com.br/2017-jul20/bruno-rodrigues-negociacao-coletiva-acaba-direitos-revoga-los $>$. Acesso em 10 de Agosto de 2017. 